\title{
PENGELOLAAN DRAINASE SECARA TERPADU UNTUK PENGENDALIAN GENANGAN DI KAWASAN SIDOKARE KABUPATEN SIDOARJO
}

\author{
Dani Eko Guntoro ${ }^{1}$, Donny Harisuseno ${ }^{2}$, Evi Nur Cahya ${ }^{2}$ \\ ${ }^{1}$ Staf Dinas Pekerjaan Umum Pengairan Kabupaten Sidoarjo \\ ${ }^{2}$ Dosen Jurusan Teknik Pengairan, Fakultas Teknik, Universitas Brawijaya, Malang \\ Email: 1dhani_water2k@yahoo.com, ${ }^{2}$ donnyhari@yahoo.com, ${ }^{2}$ evi.nur.cahya@gmail.com
}

\begin{abstract}
ABSTRAK: Banjir dan genangan di Kabupaten Sidoarjo telah menjadi permasalahan tahunan yang serius. Penelitian ini mengkaji mengenai pengelolaan drainase secara terpadu untuk pengendalian banjir dan genangan di Kawasan Sidokare, dengan pola kombinasi tertentu, yang meliputi desain saluran drainase, kolam tampungan dan pompa. Kawasan Sidokare terbagi menjadi tiga DTA, yaitu DTA Pintu Air Sepande, DTA Rumah Pompa Sidokare dan DTA Pintu Air Jl. Diponegoro. Rumus Mononobe digunakan untuk menghitung intensitas hujan dengan kala ulang tertentu. Curah hujan rancangan dihitung dengan metode Log Pearson Tipe III. Dari hasil analisis, banjir historis di Kawasan Sidokare disebabkan oleh curah hujan kala ulang 1,01 tahun dengan intensitas hujan 17,55 $\mathrm{mm} / \mathrm{jam}$. Upaya penanganan melalui pengelolaan drainase secara terpadu pada masingmasing Daerah Tangkapan Air (DTA) di Kawasan Sidokare, dapat mereduksi banjir hingga 100\%. Penanganan untuk DTA Pintu Air Sepande meliputi kombinasi saluran drainase eksisting dan kolam tampungan, DTA Rumah Pompa Sidokare menggunakan kombinasi saluran drainase eksisting, kolam tampungan dan pompa banjir eksisting, sedangkan DTA Pintu Air Jl. Diponegoro dilakukan dengan kombinasi saluran drainase eksisting, saluran tersier baru dan pompa banjir baru.
\end{abstract}

Kata kunci: pengelolaan drainase secara terpadu, banjir, genangan, reduksi banjir.

\begin{abstract}
Flood and inundation in Sidoarjo Regency had become an annual serious problem. This research has an objective to apply an integrated drainage management to controlling flood and inundation at Sidokare Region, which consists of drainage channel design, retarding pond, and pump design. Sidokare Region is divided into three catchment area, which is Sepande Sluice catchment area, Sidokare Pump House catchment area and Jl. Diponegoro Sluice catchment area. Mononobe formula was used to analyze rainfall intensity during historical floods with several return periods. Design rainfall was analyzed with Log Pearson Type III method. From the analysis, the historical floods in Sidokare Region caused by rainfall with return period of 1,01 years, showed the rainfall intensity of $17,55 \mathrm{~mm} / \mathrm{hour}$. The implementation of the integrated drainage management at each catchment area of Sidokare Region, can reduce flood up to 100\%. The inundation management for Sepande Sluice catchment area comprise with combination of existing drainage channel and a detention pond, Sidokare Pump House catchment area using combination of existing drainage channel, detention pond and the existing flood pump, whereas Jl. Diponegoro Sluice catchment area with a combination of existing drainage channel, a new tertiary channel and the new flood pump.
\end{abstract}

Keywords: integrated drainage management, flood, inundation, flood reduce.

Permasalahan air bersih, air buangan maupun air hujan sering bahkan lebih dominan dalam mewarnai permasalahan yang terjadi di daerah perkotaan, baik itu 
kota besar maupun kota kecil. Permasalahan yang ditimbulkan dari air ini adalah genangan yang sering terjadi di waktu musim penghujan.

Genangan ini muncul akibat kurang baik dan kurang tertatanya sistem drainase yang ada maupun pengaturan dari sistem yang ada. Seringkali permasalahan drainase suatu kota dianggap sama dengan kota yang lain, padahal mempunyai karakteristik yang berbeda. Begitu juga dalam hal penanggulangan masalah yang ada, seringkali menyamakan pola penyelesaian masalah dengan penyelesaian yang sudah ada di daerah lain, sedangkan sumber masalah yang dihadapi jauh berbeda dengan yang sudah ada.

Hal inilah yang membuat permasalahan drainase perkotaan menjadi lebih buruk dari tujuan semula, yaitu untuk perbaikan sistem (Ariyanto, 2012).

Pengembangan wilayah menjadi daerah industri, mengakibatkan luas lahan sawah menjadi berkurang karena dijadikan daerah pemukiman dan industri. Demikian pula dengan pembangunan gedung-gedung dan jalan raya serta bangunan fasilitas penunjang lainnya yang tidak diimbangi pembangunan sarana dan prasarana drainase yang memadai.

Hal tersebut dapat mengakibatkan respon kawasan konservasi terhadap masukan air hujan semakin rendah dan berpotensi terjadinya banjir atau genangan (BBWS Brantas, 2011 dalam Rahmawati, 2015). Dengan kata lain, pembangunan yang tidak berwawasan lingkungan, akan menyebabkan ketidak-seimbangan pada lingkungan, kemacetan lalu lintas, dan menyebabkan adanya daerah genangan air yang mengganggu (Putri, 2014).

Perkembangan kawasan terbangun yang sangat pesat, mengakibatkan alih fungsi lahan dari tempat penampungan air sementara, berubah menjadi tempat hunian penduduk, sehingga bertentangan dengan konsep pembangunan berkelanjutan. Dampaknya semakin mengurangi kemampuan sarana dan prasarana pengendali banjir pada kawasan terbangun dalam mengeringkan dan mengalirkan air ke laut.

Seiring berkembangnya pola pikir komprehensif serta semangat antisipasi perubahan iklim, mendorong munculnya paradigma baru. Yaitu konsep drainase ramah lingkungan (ekodrainase). Drainase ramah lingkungan adalah pengelolaan air kelebihan hujan melalui peresapan ke dalam tanah secara alamiah, atau mengalirkan air ke sungai tanpa melampaui kapasitas sungai (Ditjen Cipta Karya Kementerian Pekerjaan Umum, 2012).

Penyelesaian masalah genangan atau banjir yang tidak dilakukan secara terintegrasi atau terpadu, akan me-nimbulkan masalah genangan atau banjir yang semakin buruk di tempat lain. Integrasi atau keterpaduan tersebut dapat berupa penyelesaian masalah, pengembangan maupun pengelolaannya, yang akan berpengaruh pada kepentingan lainnya (Suhardjono, 2015).

Salah satu bentuk pengelolaan drainase terpadu di wilayah perkotaan adalah melalui pembuatan kolam tampungan, baik retensi, detensi maupun tampungan memanjang berupa saluran. Kolam tampungan tersebut dapat memberikan manfaat yang cukup besar, karena dapat mengurangi besarnya debit aliran (run off) di saluran, dapat menjadi tempat rekreasi masyarakat bila di sekitarnya ditata menjadi taman.

Bahkan dapat memperbaiki kandungan air tanah suatu wilayah, di samping sebagai upaya konservasi air dan pengendalian banjir secara terpadu.

Permasalahan yang ada di Kabupaten Sidoarjo, khususnya Kawasan Sidokare adalah kejadian banjir yang terjadi hampir setiap tahun pada musim penghujan. Banjir tersebut telah mengakibatkan ratusan rumah, sejumlah sekolah dan gedung perkantoran tergenang hingga $50 \mathrm{~cm}$. Genangan terjadi saat curah hujan melebihi $100 \mathrm{~mm} /$ hari dengan durasi hujan enam jam.

Dari permasalahan yang ada, maka perlu dilakukan studi atau kajian untuk mengevaluasi kondisi Daerah Tangkapan Air (DTA) pada daerah studi, sebagai upaya penanganan genangan pada daerah yang telah ada infrastruktur drainasenya. Serta menganalisa kejadian banjir historis yang pernah terjadi, agar dapat diperoleh sebuah bentuk pengelolaan drainase secara terpadu yang sesuai untuk lokasi studi.

Studi ini bertujuan untuk mengetahui kala ulang banjir historis yang pernah terjadi dan dampak penambahan volume banjir terhadap elevasi muka air di Afvoer Sidokare. Juga untuk mengetahui bentuk pengelolaan drainase secara terpadu yang sesuai, dan besarnya reduksi banjir, serta perkiraan biaya untuk upaya penanganan banjir di Kawasan Sidokare. 


\section{METODE PENELITIAN}

Kabupaten Sidoarjo berada di Provinsi Jawa Timur, terletak pada koordinat $112^{\circ} 5^{\prime}$ $112^{\circ} 9^{\prime}$ BT dan $7^{\circ} 3^{\prime}-7^{\circ} 5^{\prime}$ LS. Kawasan Sidokare sebagai lokasi studi, masuk dalam wilayah Kecamatan Sidoarjo dengan luas areal 89,57 Ha. Lokasi studi dapat dilihat pada Gambar 1.

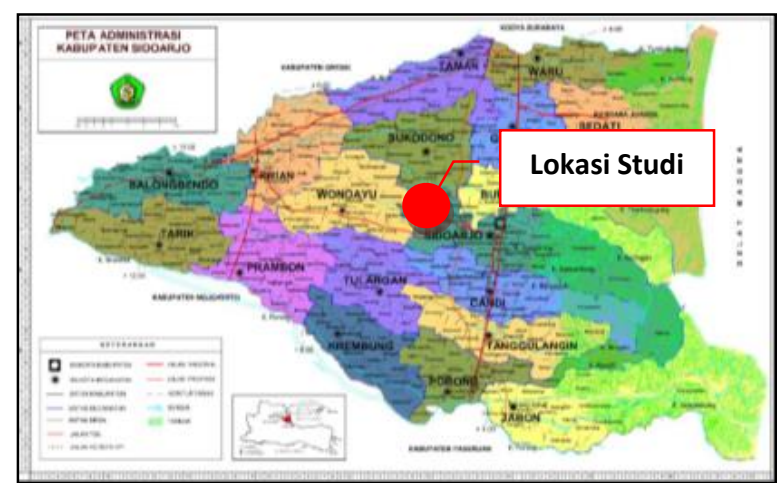

Gambar 1. Peta Kabupaten Sidoarjo

\section{Pengambilan Data}

Dalam penyelesaian studi ini diperlukan data-data pendukung, yaitu data primer dan sekunder, yang meliputi data curah hujan, data saluran drainase eksisting, data arah aliran, data rumah pompa eksisting dan outlet drainase, data tata guna lahan, data genangan, data jumlah penduduk dan foto dokumentasi.

\section{Tahapan Analisa}

1. Menentukan Daerah Tangkapan Air (DTA) lokasi studi.

2. Menganalisa data curah hujan mulai tahun 1995-2014 (20 tahun).

3. Menghitung curah hujan rerata daerah dengan metode poligon Thiessen.

4. Menghitung curah hujan rancangan metode Log Pearson Type III.

5. Menghitung intensitas curah hujan dengan rumus Mononobe.

6. Menentukan jumlah tahun kala ulang kejadian banjir historis.

7. Menghitung debit air hujan menggunakan rumus rasional yang telah dimodifikasi.

8. Menghitung debit air kotor atau buangan penduduk.

9. Menghitung debit total atau debit banjir rencana.

10. Menghitung kapasitas saluran eksisting.

11. Membandingkan kapasitas saluran eksisting dengan debit banjir rencana.
12. Membuat usulan rencana penanganan terpadu sesuai kondisi masing-masing DTA.

13. Membuat pola operasi pintu air DTA.

14. Merencanakan kolam tampungan drainase dan pola operasinya.

15. Merencanakan saluran tersier baru.

16. Mengevaluasi pompa banjir eksisting dan merencanakan pompa banjir baru beserta pola operasinya.

17. Menghitung kemampuan Afvoer Sidokare dalam menerima tambahan volume banjir dari lokasi studi.

18. Menghitung reduksi banjir setelah dilakukan penanganan secara terpadu.

19. Menghitung perkiraan biaya untuk penanganan terpadu.

\section{Curah Hujan Rerata Daerah}

Perhitungan curah hujan rerata daerah dengan metode poligon Thiessen diperlukan untuk mengetahui pengaruh stasiun hujan tertentu, terhadap luasan daerah yang dipengaruhinya. Persamaannya sebagai berikut:

$\overline{\mathrm{P}}=\frac{\mathrm{A}_{1} \mathrm{P}_{1}+\mathrm{A}_{2} \mathrm{P}_{2}+\ldots+\mathrm{A}_{\mathrm{n}} \mathrm{P}_{\mathrm{n}}}{\mathrm{A}_{1}+\mathrm{A}_{2}+\ldots+\mathrm{A}_{\mathrm{n}}}$

dengan:

$\overline{\mathrm{P}} \quad=$ Hujan rerata daerah $(\mathrm{mm})$

$\mathrm{P}_{1}, \mathrm{P}_{2}, \ldots, \mathrm{P}_{\mathrm{n}}=$ Hujan pada stasiun 1, 2, ....., n (mm)

$\mathrm{A}_{1}, \mathrm{~A}_{2}, \ldots, \mathrm{A}_{\mathrm{n}}=$ Luas daerah yang mewakili stasiun $1,2, \ldots ., \mathrm{n}$

\section{Curah Hujan Rancangan Metode Log Pearson Type III}

Curah hujan rancangan metode Log Pearson Tipe III dapat digunakan pada semua sebaran data tanpa harus memenuhi syarat koefisien kepencengan (skewness) dan koefisien kepuncakan (kurtosis). Persamaannya sebagai berikut:

$\log \mathrm{X}=\log \overline{\mathrm{X}}+\mathrm{G} \cdot \mathrm{Sd}$

dengan:

$\log \mathrm{X}=$ Nilai logaritma dari curah hujan rancangan dengan kala ulang tertentu

$\log \overline{\mathrm{X}}=$ Rata-rata logaritma dari hujan ratarata maksimum daerah

$\mathrm{G}=$ Merupakan konstanta yang didapatkan dari tabel Log Pearson Type III dari hubungan antara $\mathrm{C}_{\mathrm{s}}$ dan periode ulang $(\mathrm{T})$. 
$\mathrm{Sd}$

$$
=\text { Simpangan baku }
$$

\section{Intensitas Hujan}

Intensitas hujan di kawasan perkotaan dapat dihitung dengan rumus Mononobe, sebagai berikut (Suhardjono, 2015):

$\mathrm{I}=\frac{\mathrm{R}_{24}}{24}\left(\frac{24}{\mathrm{~T}_{\mathrm{c}}}\right)^{2 / 3}$

dengan:

$$
\begin{aligned}
\mathrm{I}= & \text { intensitas hujan selama waktu } \\
& \text { konsentrasi (mm/jam) } \\
\mathrm{R}_{24}= & \text { curah hujan maksimum harian } \\
& \text { dalam 24 jam (mm/jam) dengan } \\
& \text { kala ulang tertentu } \\
\mathrm{T}_{\mathrm{c}}= & \text { waktu konsentrasi (jam) } \\
2 / 3= & \text { konstanta }
\end{aligned}
$$

\section{Jumlah Tahun Kala Ulang}

Perkiraan jumlah tahun rancangan didasarkan pada volume banjir yang terjadi, dibagi dengan lama genangan yang terjadi. Tahapan analisa penentuan kala ulang banjir historis, sebagai berikut:

1. Menganalisa volume genangan sampai dengan elevasi banjir tertinggi.

2. Menganalisa luas lahan yang tergenang dan tidak tergenang.

3. Menghitung volume air yang ter-tampung.

4. Menghitung kapasitas saluran drainase eksisting.

5. Mengetahui volume air yang meluap/ melimpas.

6. Mengubah besarnya volume air menjadi debit banjir historis.

7. Menentukan kala ulang banjir historis berdasarkan analisa intensitas hujan.

\section{Debit Akibat Hujan}

Debit akibat hujan untuk drainase perkotaan biasanya dihitung menggunakan rumus Rasional. Di bawah ini rumus Rasional modifikasi (Suhardjono, 2015):

$$
\mathrm{Q}=0,278 \text {. Cs . C . I . A }
$$

dengan:

$$
\begin{aligned}
\mathrm{Q}= & \text { debit banjir rancangan }\left(\mathrm{m}^{3} / \mathrm{dt}\right) \\
\mathrm{C}= & \text { koefisien limpasan } \\
\mathrm{I}= & \text { intensitas hujan pada durasi yang } \\
& \text { sama dengan waktu konsentrasi dan } \\
& \text { pada periode ulang hujan tertentu } \\
& (\mathrm{mm} / \mathrm{jam})
\end{aligned}
$$

$$
\begin{aligned}
\mathrm{A}= & \text { luas daerah pengaliran }\left(\mathrm{km}^{2}\right) \\
\mathrm{Cs}= & \text { koefisien hambatan akibat } \\
& \text { tampungan } \\
0,278= & \begin{array}{l}
\text { faktor konversi (agar satuan } \\
\text { menjadi } \left.\mathrm{m}^{3} / \mathrm{dt}\right)
\end{array}
\end{aligned}
$$

\section{HASIL DAN PEMBAHASAN}

\section{Batas Daerah Tangkapan Air (DTA)}

Kawasan Sidokare sebagaimana disajikan pada Gambar 2, terbagi menjadi tiga DTA, yaitu DTA Pintu Air Sepande (bagian barat), DTA Rumah Pompa Sidokare (bagian tengah) dan DTA Pintu Air Jl. Diponegoro (bagian timur). Ketiga outlet DTA tersebut mengalir menuju Afvoer Sidokare sebagai sungai utama (main drain).

\section{Analisa Curah Hujan}

Data curah hujan 20 tahun, mulai tahun 1995-2014, digunakan dalam analisis hidrologi. Namun untuk mendapatkan data hujan yang cukup handal, diperlukan beberapa pengujian, meliputi uji konsistensi dengan analisa kurva massa ganda (double mass curve analysis) dan analisa deret berkala secara statistik, yang meliputi uji ketidakadaan trend, uji stasioner dan uji persistensi.

Dari hasil pengujian diketahui data keempat stasiun hujan yang digunakan, yaitu Stasiun Durungbedug, Stasiun Sidoarjo, Stasiun Sumput dan Stasiun Kludan, bersifat konsisten. Sedangkan dari uji deret berkala secara statistik, menunjukkan bahwa pada uji ketidakadaan trend, data empat stasiun bersifat independen.

Pada uji stasioner, data empat stasiun bersifat stabil. Sedangkan untuk uji persistensi, data dari tiga stasiun bersifat acak, sedangkan data dari satu stasiun tidak bersifat acak. Sehingga data dari tiga stasiun dapat diterima dan cukup handal untuk dapat digunakan dalam analisis hidrologi selanjutnya.

Dalam perhitungan curah hujan rerata daerah menggunakan metode poligon Thiessen, diketahui bahwa daerah studi dipengaruhi seluruhnya oleh Stasiun Sidoarjo (162), sebagaimana dapat dilihat pada Gambar 3. Di mana data hujan Stasiun Sidoarjo dalam pengujian sebelumnya, telah memenuhi syarat dan cukup handal untuk digunakan dalam analisis hidrologi. 


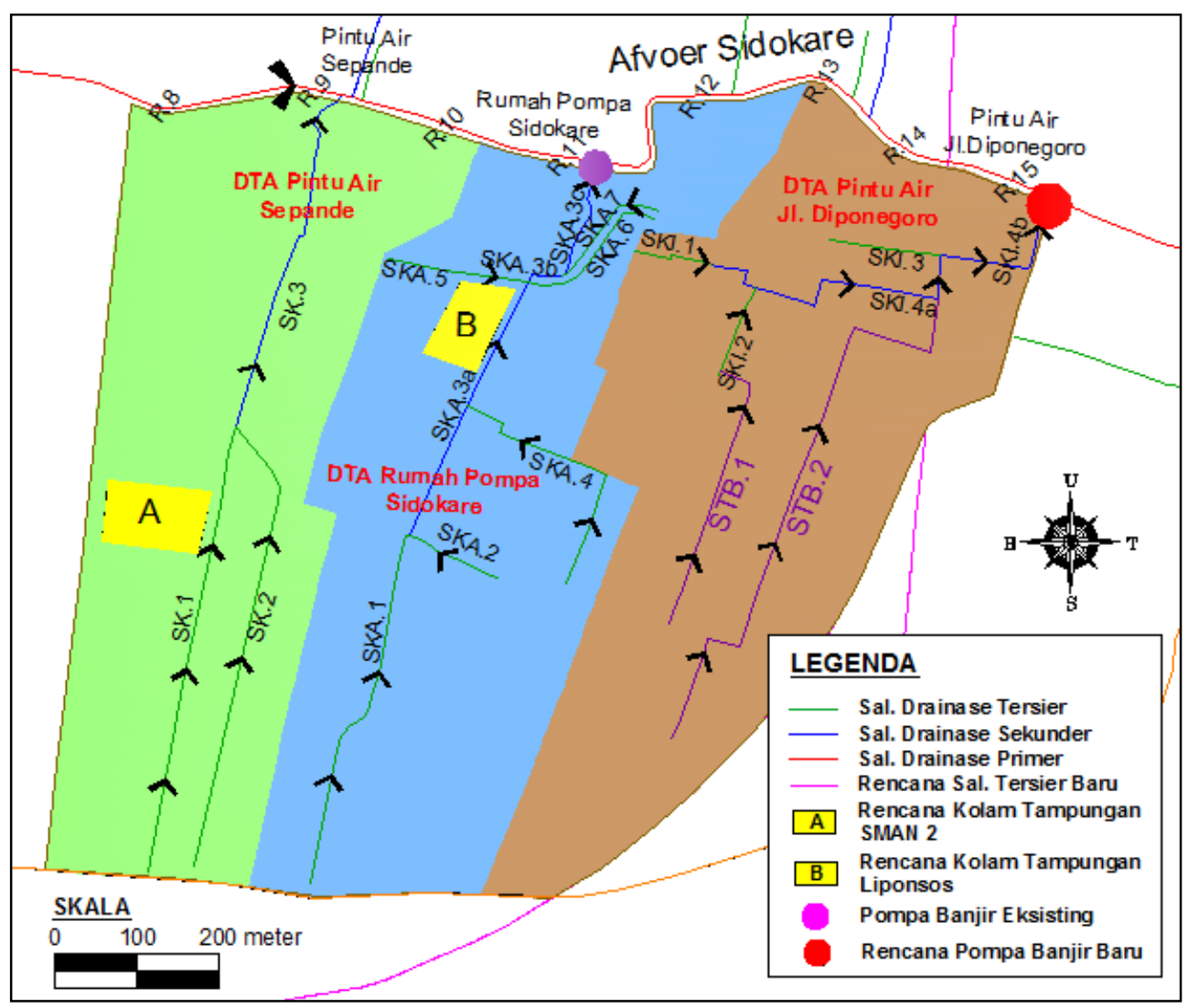

Gambar 2. Jaringan Drainase Kawasan Sidokare

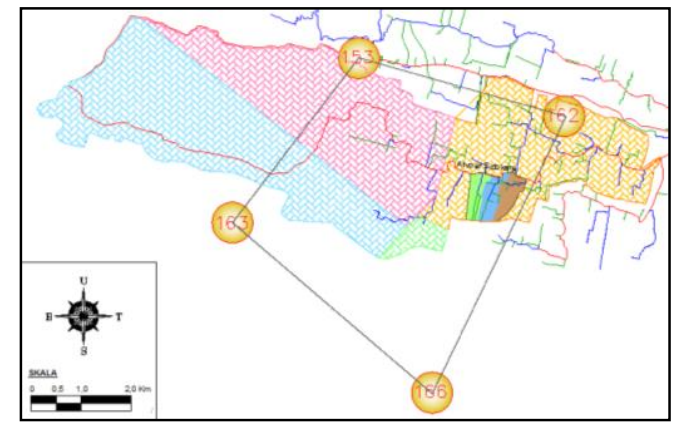

Gambar 3.

Pengaruh Stasiun Hujan Sidoarjo (162)

\section{Curah Hujan Rancangan Metode Log Pearson Type III}

Tabel 1. Curah Hujan Rancangan Kala Ulang Tertentu

\begin{tabular}{|c|c|}
\hline $\begin{array}{c}\mathrm{Tr} \\
\text { (tahun) }\end{array}$ & $\begin{array}{c}\mathrm{X}_{\mathrm{T}} \\
(\mathrm{mm})\end{array}$ \\
\hline 1.01 & 74.26 \\
2 & 98.73 \\
5 & 118.27 \\
\hline
\end{tabular}

Pada studi ini, perencanaan drainase di kawasan perumahan di perkotaan menggunakan kala ulang 1,01 tahun, 2 tahun dan 5 tahun. Hasil perhitungan curah hujan rancangan $\left(\mathrm{X}_{\mathrm{T}}\right)$ dengan Metode Log Pearson Type III untuk kala ulang tertentu (Tr) dapat dilihat pada Tabel 1.

\section{Intensitas Hujan}

Tabel 2. Intensitas Hujan Berdasarkan Kala Ulang

\begin{tabular}{|c|c|c|c|}
\hline $\begin{array}{c}\text { Kala } \\
\text { Ulang }\end{array}$ & $\begin{array}{c}\text { Peluang } \\
\text { Kejadian }\end{array}$ & $\begin{array}{c}\text { Curah Hujan } \\
\text { Rancangan } \\
(\mathrm{mm})\end{array}$ & $\begin{array}{c}\text { Intensitas } \\
\text { Hujan } \\
\text { (mm/jam) }\end{array}$ \\
\hline 1.01 & 99 & 74.26 & 16.503 \\
2 & 50 & 98.73 & 21.939 \\
5 & 20 & 118.27 & 26.283 \\
\hline
\end{tabular}

Perhitungan intensitas curah hujan bertujuan untuk mengetahui tinggi hujan historis yang mengakibatkan banjir. Menurut hasil pengamatan, informasi instansi terkait dan historis hujan, bahwa durasi hujan di lokasi studi, rata-rata terjadi dalam enam jam.

Hasil perhitungan intensitas hujan dengan rumus Mononobe, selanjutnya akan dibandingkan dengan perhitungan genangan historis untuk mendapatkan tahun kala ulang banjir historis. Pada Tabel 2 disajikan hasil analisa intensitas hujan berdasarkan kala ulang. 


\section{Jumlah Tahun Kala Ulang}

Hasil pengamatan lama genangan yang terjadi berdasarkan banjir historis adalah selama dua hari, di mana terdapat satu hari efektif (24 jam) dengan asumsi air tidak bertambah dan tidak berkurang.

Analisis volume genangan menggunakan peta kontur atau topografi, diperoleh volume sebesar 419.530,30 $\mathrm{m}^{3}$ untuk tinggi genangan $0,50 \mathrm{~m}$ dari permukaan tanah. Dengan daerah tergenang seluas $64.068,92 \mathrm{~m}^{2}(29,61 \%$ dari luas Kawasan Sidokare), maka diperoleh volume tertampung sebesar 124.213,59 $\mathrm{m}^{3}$. Dari volume tersebut kemudian dikurangi kapasitas saluran drainase eksisting sebesar $8427,23 \mathrm{~m}^{3}$ dan hasil analisa pemompaan pada saat kejadian banjir sebesar 100.800,00 $\mathrm{m}^{3}$. Diperoleh volume limpasan/luapan air banjir sebesar 14.986,36 $\mathrm{m}^{3}$. Volume genangan tersebut bila diubah menjadi intensitas hujan, diperoleh nilai intensitas hujan historis sebesar $17,55 \mathrm{~mm} / \mathrm{jam}$. Nilai tersebut mendekati nilai intensitas hujan rencana kala ulang banjir 1,01 tahun $(16,503$ $\mathrm{mm} / \mathrm{jam}$ ). Selanjutnya perhitungan kala ulang yang dipakai dalam analisis adalah kala ulang 1,01 tahun, 2 tahun dan 5 tahun.

\section{Debit Akibat Hujan}

Dengan luas Kawasan Sidokare sebesar 89,57 $\mathrm{Ha}$ atau 0,8957 $\mathrm{km}^{2}$, perhitungan debit air hujan untuk tiap-tiap DTA saluran drainase menggunakan persamaan rasional modifikasi dengan memasukkan koefisien penampungan (Cs) sebagai angka koreksi terhadap banyaknya hambatan bangunan di daerah perkotaan. Selanjutnya debit akibat hujan ditambahkan dengan debit air kotor atau buangan penduduk, sehingga diperoleh debit total atau debit banjir rencana.

\section{Kapasitas Saluran Drainase Eksisting}

Hasil perbandingan kapasitas saluran drainase eksisting dengan debit banjir rencana kala ulang 1,01 tahun, 2 tahun dan 5 tahun dapat dilihat pada Tabel 3.

\section{DTA Pintu Air Sepande}

Untuk debit rencana kala ulang 1,01 tahun cukup aman, karena saluran eksisting mampu menampung seluruh debit banjir rencana. Sedangkan untuk kala ulang 2 tahun dan 5 tahun terdapat satu saluran eksisting yang meluap.
2. DTA Rumah Pompa Sidokare

Untuk debit rencana kala ulang 1,01 tahun terdapat empat saluran eksisting yang meluap. Sedangkan untuk kala ulang 2 tahun dan 5 tahun, terdapat enam dan tujuh saluran eksisting yang meluap.

3. DTA Pintu Air Jl. Diponegoro

Untuk debit rencana kala ulang 1,01 tahun terdapat tiga saluran eksisting yang meluap. Sedangkan untuk kala ulang 2 tahun dan 5 tahun terdapat empat saluran eksisting yang meluap.

Tabel 3. Perbandingan Kapasitas Saluran Eksisting dan Debit Banjir Rencana Berdasarkan Kala Ulang

\begin{tabular}{|c|c|c|c|c|}
\hline \multirow[b]{2}{*}{$\begin{array}{c}\text { Ruas } \\
\text { Saluran }\end{array}$} & \multirow{2}{*}{$\begin{array}{c}\text { Kapasitas } \\
\text { Saluran } \\
\text { Eksisting } \\
\left(\mathrm{m}^{3} / \mathrm{dt}\right)\end{array}$} & \multicolumn{3}{|c|}{ Debit Banjir Rencana } \\
\hline & & $\begin{array}{c}1,01 \\
\text { Tahun } \\
\left(\mathrm{m}^{3} / \mathrm{dt}\right)\end{array}$ & $\begin{array}{c}2 \text { Tahun } \\
\left(\mathrm{m}^{3} / \mathrm{dt}\right)\end{array}$ & $\begin{array}{l}5 \text { Tahun } \\
\left(\mathrm{m}^{3} / \mathrm{dt}\right)\end{array}$ \\
\hline \multicolumn{5}{|c|}{ A. DTA Pintu Air Sepande } \\
\hline SK.1 & 0.5544 & 0.3407 & 0.4406 & 0.5278 \\
\hline SK.2 & 0.3300 & 0.1775 & 0.2295 & 0.2749 \\
\hline SK.3 & 0.8910 & 0.7449 & 0.9606 & 1.1508 \\
\hline Jumlah & 1.7754 & 1.2631 & 1.6307 & 1.9535 \\
\hline \multicolumn{5}{|c|}{ B. DTA Rumah Pompa Sidokare } \\
\hline SKA.1 & 0.3300 & 0.2217 & 0.2870 & 0.3438 \\
\hline SKA.2 & 0.3960 & 0.4036 & 0.5253 & 0.6293 \\
\hline SKA.3a & 0.6600 & 0.6997 & 0.9034 & 1.0823 \\
\hline SKA.3b & 0.8316 & 0.7909 & 1.0208 & 1.2230 \\
\hline SKA.3c & 0.9438 & 0.8162 & 1.0527 & 1.2611 \\
\hline SKA.4 & 0.3300 & 0.3403 & 0.4410 & 0.5283 \\
\hline SKA.5 & 0.3630 & 0.1127 & 0.1464 & 0.1754 \\
\hline SKA.6 & 0.5082 & 0.0626 & 0.0813 & 0.0975 \\
\hline SKA.7 & 0.1848 & 0.2022 & 0.2629 & 0.3149 \\
\hline Jumlah & 4.5474 & 3.6499 & 4.7209 & 5.6556 \\
\hline \multicolumn{5}{|c|}{ C. DTA Pintu Air Jl. Diponegoro } \\
\hline SKI.1 & 0.4158 & 0.3299 & 0.4297 & 0.5147 \\
\hline SKI.2 & 0.3300 & 0.4244 & 0.5524 & 0.6618 \\
\hline SKI.3 & 0.2970 & 0.2993 & 0.3893 & 0.4663 \\
\hline SKI.4a & 0.7128 & 0.8910 & 1.1528 & 1.3810 \\
\hline SKI.4b & 2.9700 & 0.9408 & 1.2154 & 1.4561 \\
\hline Jumlah & 4.7256 & 2.8853 & 3.7395 & 4.4799 \\
\hline
\end{tabular}

\section{Rencana Penanganan Banjir}

Pengelolaan drainase secara terpadu untuk pengendalian genangan di Kawasan Sidokare Kabupaten Sidoarjo, didefinisikan sebagai upaya penanganan genangan pada jaringan drainase perkotaan yang dilakukan secara terpadu dengan pola kombinasi tertentu. Penanganan yang diusulkan lebih mengarah pada konservasi air di musim hujan maupun musim kemarau.

Kendala keterbatasan lahan yang ada, tidak memungkinkan untuk dilakukan pelebaran maupun memperdalam saluran, karena muka air tanah pada musim hujan hanya satu meter dari permukaan tanah. 
Kombinasi penanganan yang diusulkan untuk Kawasan Sidokare adalah:

1. Optimalisasi saluran drainase eksisting,

2. Pola operasi pintu air,

3. Perencanaan kolam tampungan sebagai sarana konservasi air dan rekreasi,

4. Pembuatan saluran tersier baru,

5. Pengoperasian pompa banjir eksisting,

6. Penambahan pompa banjir baru.

Adapun upaya penanganan genangan disesuaikan dengan kondisi masing-masing DTA di daerah studi.

1. DTA Pintu Air Sepande

Penanganan direncanakan menggunakan kombinasi saluran drainase eksisting dan kolam tampungan.

2. DTA Rumah Pompa Sidokare

Penanganan direncanakan menggunakan kombinasi saluran drainase eksisting, kolam tampungan dan pompa banjir eksisting.

3. DTA Pintu Air Jl. Diponegoro

Penanganan direncanakan menggunakan kombinasi saluran drainase eksisting, saluran tersier baru dan pompa banjir baru.

\section{Pola Operasi Pintu Air di Outlet DTA}

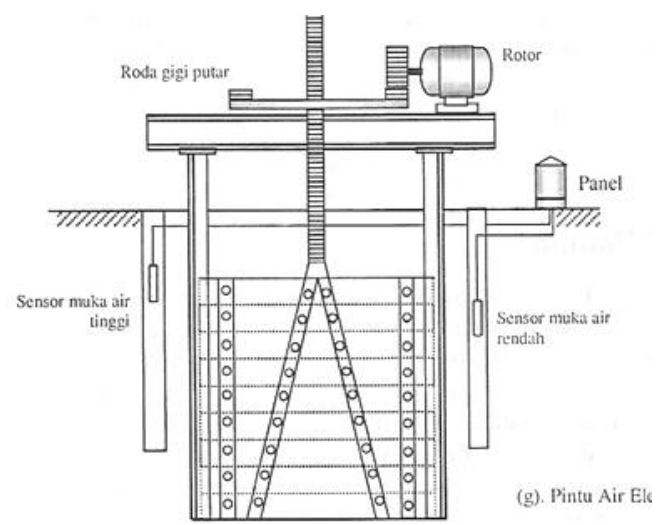

Gambar 4. Pintu Air Elektrik

Diperlukan peningkatan kinerja pintu air yang ada di outlet DTA dengan mengubahnya menjadi pintu air elektrik, sebagaimana Gambar 4 (Suripin, 2004). Pola operasi pintu air elektrik sebagai berikut:

1. Pintu air elektrik digerakkan oleh motor yang mendapat suplai aliran listrik.

2. Aliran listrik diatur oleh sensor yang dihubungkan dengan kondisi muka air.

3. Pada saat muka air di hilir tinggi, aliran listrik ke motor menyebabkan putaran roda putar bergigi menutup pintu.
4. Sebaliknya pada saat muka air di hilir rendah, aliran listrik menyebabkan putaran yang membuka pintu.

\section{Kolam Tampungan Drainase}

Kolam tampungan dalam studi ini, sebagaimana Gambar 2, adalah kolam yang berfungsi sebagai tampungan sementara (detention pond) pada saat musim hujan. Sedangkan pada musim kemarau berfungsi sebagai kolam tandon, dengan cara menahan air sisa musim hujan pada kolam tampungan. Sehingga dapat difungsikan sebagai tempat pemancingan, taman, hutan kota maupun fungsi konservasi air dan udara serta fungsifungsi lainnya.

\section{a. Kolam Tampungan SMAN 2}

Lokasi rencana untuk pembuatan Kolam Tampungan SMAN 2 pada Gambar 2 diberi notasi huruf A. Yaitu lapangan/tanah kosong di sebelah selatan SMAN 2 Sidoarjo. Data teknis Kolam Tampungan SMAN 2 sebagai berikut:

- Panjang rencana $\quad=100 \mathrm{~m}$

- Lebar rencana $\quad=60 \mathrm{~m}$

- Tinggi rencana $=2,5 \mathrm{~m}$

(diukur dari permukaan tanah, dengan 0,5 m sebagai tinggi jagaan)

- Kemiringan talud $=1: 1$

Kolam Tampungan SMAN 2 memiliki kapasitas maksimum sebesar $16.614 \mathrm{~m}^{3}$. Fungsinya melayani DTA Pintu Air Sepande dan mampu untuk menampung volume air dari SK.1 kala ulang 2 tahun dan 5 tahun. Tujuan dibuatnya Kolam Tampungan SMAN 2 adalah untuk mengurangi beban saluran sekunder SK.3. Proses pengisian kolam tampungan pada musim hujan dilakukan dengan menggunakan satu unit pompa inlet dengan kapasitas $0,5 \mathrm{~m}^{3} / \mathrm{dt} / \mathrm{unit}$. Pompa tersebut dioperasikan saat hujan turun dengan lebat dan muka air di saluran drainase mulai mencapai freeboard.

Untuk kala ulang 1,01 tahun, Kolam Tampungan SMAN 2 belum difungsikan, karena seluruh saluran drainase eksisting yang ada masih mampu menampung debit banjir rencana. Sedangkan pada kala ulang 2 tahun dan 5 tahun, pengisian kolam tampungan untuk volume air sebesar 9.517,66 $\mathrm{m}^{3}$ dan 11.401,56 $\mathrm{m}^{3}$ membutuhkan waktu 5,29 jam dan 6,33 jam.

Pada saat musim kemarau, fungsi kolam tampungan lebih mengarah pada 
kolam tandon untuk konservasi air, kolam pemancingan dan rekreasi bagi masyarakat. Untuk itu, maka air hujan yang turun di penghujung musim hujan harus ditampung seluruhnya di dalam kolam, dan tidak dibuang ke Afvoer Sidokare.

\section{b. Kolam Tampungan Liponsos}

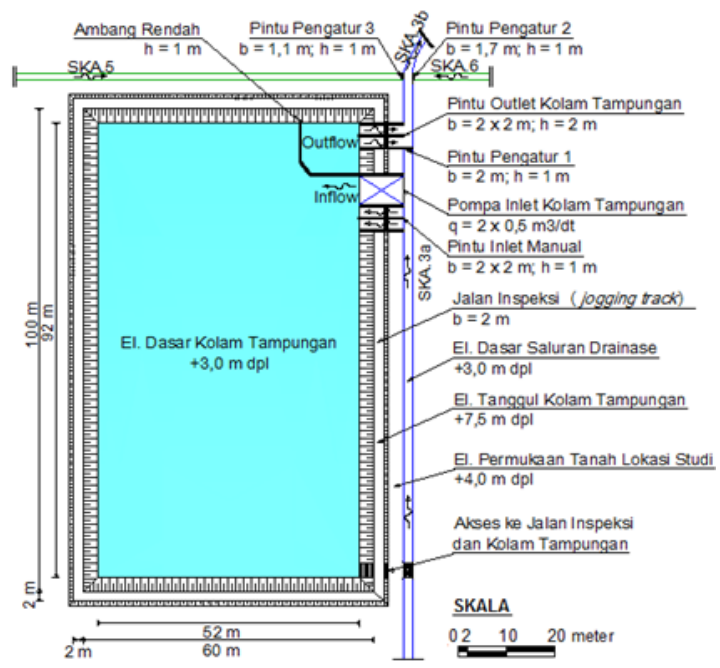

Gambar 5. Kolam Tampungan Liponsos

Lokasi rencana untuk pembuatan Kolam Tampungan Liponsos pada Gambar 5 diberi notasi huruf B. Yaitu lapangan/tanah kosong di sebelah barat Kantor Liponsos Disnaker Sidoarjo. Data teknis Kolam Tampungan Liponsos sebagai berikut:

- Panjang rencana $\quad=100 \mathrm{~m}$

- Lebar rencana $\quad=60 \mathrm{~m}$

- Tinggi rencana $=3,5 \mathrm{~m}$

(diukur dari permukaan tanah, dengan 0,5 m sebagai tinggi jagaan)

- Kemiringan talud $=1: 1$

Kolam Tampungan Liponsos memiliki kapasitas maksimum sebesar $21.568 \mathrm{~m}^{3}$. Fungsinya melayani DTA Rumah Pompa Sidokare dan mampu menampung kelebihan volume air dari saluran SKA.1, SKA.2, SKA. 3a dan SKA.4, untuk kala ulang 1,01 tahun $\left(1.244,64 \mathrm{~m}^{3}\right), 2$ tahun $\left(10.448,47 \mathrm{~m}^{3}\right)$ dan 5 tahun $\left(18.742,54 \mathrm{~m}^{3}\right)$.

Proses pengisian kolam tampungan pada musim hujan dilakukan dengan menggunakan dua unit pompa inlet dengan kapasitas $0,5 \mathrm{~m}^{3} / \mathrm{dt} / \mathrm{unit}$, sebagaimana pada Gambar 5. Pompa tersebut dioperasikan saat hujan turun dengan lebat dan muka air di saluran drainase mulai mencapai freeboard. Air yang dipompakan ke dalam Kolam Tampungan Liponsos, adalah kelebihan air dari saluran SKA.1, SKA.2, SKA.3a dan SKA.4, agar tidak meluap ke jalan dan permukiman/perumahan penduduk.

Untuk kala ulang 1,01 tahun, lama pengisian air ke dalam kolam adalah 0,35 jam. Sedangkan kala ulang 2 tahun dan 5 tahun adalah 2,90 jam dan 5,21 jam. Cukup optimal dengan kondisi genangan historis yang diakibatkan oleh durasi hujan enam jam.

Pelepasan air dari kolam tampungan pada musim hujan harus dilakukan secara periodik, agar kolam tampungan tidak sampai overcapacity dan dapat menampung air dari curah hujan berikutnya. Pelepasan air dapat dilakukan bila muka air banjir di Afvoer Sidokare telah turun di bawah elevasi dasar outlet saluran drainase eksisting $(+3,0 \mathrm{~m}$ dpl), dan kondisi air di saluran sekunder SKA.3b dan SKA.3c telah kosong.

Pada saat musim kemarau, fungsi kolam tampungan lebih mengarah pada kolam tandon untuk konservasi air, kolam pemancingan dan rekreasi bagi masyarakat. Untuk itu, maka air hujan yang turun di penghujung musim hujan harus ditampung seluruhnya di dalam kolam, dan tidak dibuang ke Afvoer Sidokare.

\section{Saluran Tersier Baru}

Pembuatan saluran tersier baru sebagaimana dapat dilihat pada Gambar 2, disebabkan karena pada DTA Pintu Air Jl. Diponegoro tidak terdapat lahan yang memungkinkan untuk dibuat kolam tampungan sementara sebagai upaya untuk mereduksi debit banjir rencana. Maka alternatif yang dapat dipilih adalah membuat saluran tersier baru di tengah-tengah jalan perumahan yang berfungsi untuk mengurangi beban saluran yang ada dan sebagai sarana konservasi air. Penampang rencana Saluran Tersier Baru 1 dapat dilihat pada Gambar 6.

Saluran tersier baru yang akan dibuat, yaitu Saluran Tersier Baru 1 (STB.1) dan Saluran Tersier Baru 2 (STB.2). STB.1 berfungsi mengurangi beban saluran tersier SKI.2. Dengan adanya STB.1, kelebihan debit dari SKI.2 dapat ditampung seluruhnya oleh STB.1. Sedangkan STB.2 berfungsi mengurangi beban saluran SKI.4a. Dengan adanya STB.2, kelebihan debit dari SKI.4a dapat ditampung seluruhnya oleh STB.2. 


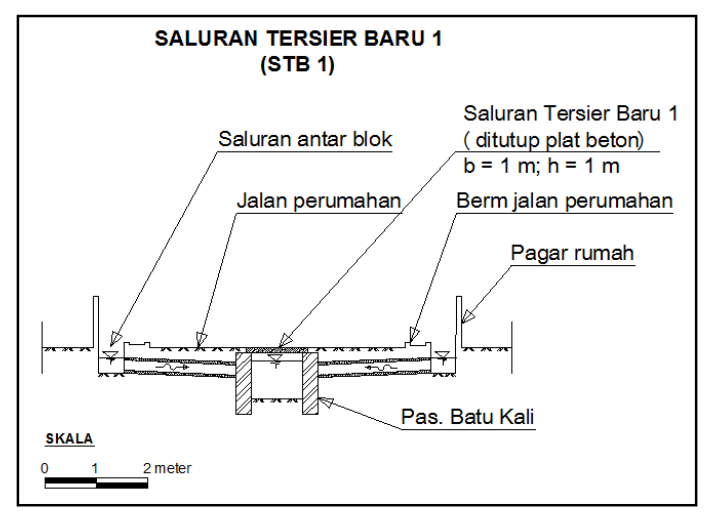

Gambar 6. Saluran Tersier Baru 1

Untuk kala ulang 1,01 tahun, beban debit saluran sekunder SKI.2 sebesar 0,4244 $\mathrm{m}^{3} / \mathrm{dt}$ dan meluap karena melampaui kapasitas saluran eksisting, menjadi berkurang karena kelebihan air sebesar $0,0944 \mathrm{~m}^{3} / \mathrm{dt}$ masuk ke STB.1, sehingga SKI.2 aman. Sedangkan pada saluran sekunder SKI.4a, beban debit berkurang dari $0,8910 \mathrm{~m}^{3} / \mathrm{dt}$ menjadi $0,7128 \mathrm{~m}^{3} / \mathrm{dt}$, karena kelebihan air sebesar $0,7001 \mathrm{~m}^{3} / \mathrm{dt}$ masuk ke STB.2, sehingga SKI.4a aman. Demikian juga pengurangan beban debit pada kala ulang 2 tahun dan 5 tahun.

\section{Pompa Banjir}

Pompa banjir sebagaimana pada Gambar 2, merupakan alternatif terakhir yang dipilih dalam pengendalian genangan melalui upaya konservasi air. Pengoperasian pompa banjir bertujuan untuk membuang kelebihan debit ke afvoer, apabila saluran drainase dan kolam tampungan tidak mampu menampung debit banjir rencana, karena telah melebihi perencanaan yang ada.

\section{a. DTA Pintu Air Sepande}

Debit banjir rencana pada DTA Pintu Air Sepande dapat ditangani dengan saluran drainase eksisting dan Kolam Tampungan SMAN 2, sehingga tidak lagi memerlukan pompa banjir.

b. DTA Rumah Pompa Sidokare

Di outlet DTA Rumah Pompa Sidokare terdapat dua unit pompa banjir eksisting dengan kapasitas setiap pompa adalah $350 \mathrm{l} / \mathrm{dt}$ atau $0,35 \mathrm{~m} 3 / \mathrm{dt}$. Fungsinya dapat dioptimalkan dengan mengacu pada Standard Operation Prosedure (SOP) yang ada. Namun tetap diperlukan kedisiplinan petugas operasi pompa.

Pada kondisi debit banjir rencana kala ulang 1,01 tahun, kelebihan air yang harus dipompa sebesar $0,2561 \mathrm{~m}^{3} / \mathrm{dt}$, yang berasal dari SKA.7, SKA.3b dan SKA.3c. Pemompaan ini bertujuan untuk mengosongkan saluran sekunder SKA.3b dan SKA.3c, agar saat air di afvoer mulai surut, air yang tertampung di Kolam Tampungan Liponsos dapat segera dialirkan keluar menuju Afvoer Sidokare melalui saluran SKA.3b dan SKA.3c. Untuk durasi hujan 6 jam, waktu yang diperlukan untuk memompa kelebihan air dengan pompa eksisting adalah selama 2,19 jam.

Sedangkan untuk kala ulang 2 tahun dan 5 tahun, kelebihan air yang harus dipompa sebesar $0,3953 \mathrm{~m}^{3} / \mathrm{dt}$ dan 0,5102 $\mathrm{m}^{3} / \mathrm{dt}$. Dengan durasi hujan enam jam, diperlukan waktu pemompaan dengan pompa eksisting selama 3,39 jam dan 4,37 jam.

c. DTA Pintu Air Jl. Diponegoro

Kondisi eksisting outlet DTA Pintu Air Jl. Diponegoro hanya terdapat pintu air yang menjadi bangunan pengatur pada saat terjadi banjir. Diusulkan untuk dipasang pompa banjir dengan dengan kapasitas 1 unit x 0,5 $\mathrm{m}^{3} / \mathrm{dt}$, atau $500 \mathrm{lt} / \mathrm{dt}$ untuk memompa air dari DTA Pintu Air Jl. Diponegoro ke Afvoer Sidokare.

Pada kondisi banjir rencana kala ulang 1,01 tahun, kelebihan air yang harus dipompa sebesar $0,0023 \mathrm{~m}^{3} / \mathrm{dt}$. Untuk durasi hujan enam jam, waktu yang diperlukan untuk memompa kelebihan air tersebut dengan pompa banjir baru dengan kapasitas $0,5 \mathrm{~m}^{3} / \mathrm{dt}$ adalah selama 0,03 jam.

Sedangkan untuk kala ulang 2 tahun dan 5 tahun, kelebihan air yang harus dipompa sebesar $0,1061 \mathrm{~m}^{3} / \mathrm{dt}$ dan 0,2683 $\mathrm{m}^{3} / \mathrm{dt}$. Dengan durasi hujan enam jam, diperlukan waktu pemompaan dengan pompa banjir baru selama 1,27 jam dan 3,22 jam.

\section{Kemampuan Afvoer Sidokare Menerima Tambahan Volume Banjir}

Berdasarkan hasil analisa, Afvoer Sidokare yang memiliki parapet (tanggul sungai tambahan) setinggi $0,50 \mathrm{~m}$ dan lebar rata-rata antar parapet kanan kiri 23,17 m, sepanjang 4.767,55 m dari lokasi studi hingga outlet Sub DAS Afvoer Sidokare, mampu menerima volume banjir tambahan sebesar 55.235,47 $\mathrm{m}^{3}$. Penambahan volume banjir dari Kawasan Sidokare ke Afvoer Sidokare pada kala ulang 1,01 tahun sebesar $5.579,52 \mathrm{~m}^{3}$, dengan tinggi muka air di afvoer bertambah $0,05 \mathrm{~m}$ dari muka air maksimum. Sedangkan pada kala ulang 2 
tahun terdapat penambahan ketinggian muka air di afvoer setinggi $0,10 \mathrm{~m}$, dengan tambahan volume banjir sebesar $10.831,92$ $\mathrm{m}^{3}$. Pada kala ulang 5 tahun penambahan ketinggian muka air di afvoer setinggi 0,15 $\mathrm{m}$, dengan tambahan volume banjir sebesar $16.814,88 \mathrm{~m}^{3}$.

\section{Reduksi Banjir}

Besarnya reduksi banjir setelah dilakukan penanganan secara terpadu dapat dilihat pada Tabel 4.

\begin{tabular}{|c|c|c|c|c|c|c|c|c|}
\hline \multirow[b]{2}{*}{ No. } & \multirow[b]{2}{*}{ Jenis Pengendalian Banjir } & \multicolumn{3}{|c|}{ Debit Rencana $\left(\mathrm{m}^{3} / \mathrm{dt}\right)$} & \multicolumn{3}{|c|}{ Reduksi Banjir (\%) } & \multirow[b]{2}{*}{ Keterangan } \\
\hline & & \begin{tabular}{|l|} 
Kala Ulang \\
1,01 Tahun
\end{tabular} & $\begin{array}{c}\text { Kala Ulang } \\
2 \text { Tahun }\end{array}$ & $\begin{array}{c}\text { Kala Ulang } \\
5 \text { Tahun }\end{array}$ & $\begin{array}{l}\text { Kala Ulang } \\
\text { 1,01 Tahun }\end{array}$ & $\begin{array}{c}\text { Kala Ulang } \\
2 \text { Tahun }\end{array}$ & $\begin{array}{l}\text { Kala Ulang } \\
5 \text { Tahun }\end{array}$ & \\
\hline A. & DTA Pintu Air Sepande & 1.2631 & 1.3273 & 1.5901 & \multirow{3}{*}{$\begin{array}{c}100.00 \\
0\end{array}$} & \multirow{3}{*}{$\begin{array}{l}66.80 \\
33.20\end{array}$} & \multirow{3}{*}{$\begin{array}{l}66.80 \\
33.20\end{array}$} & \multirow{3}{*}{$\begin{array}{l}\text { Kombinasi saluran } \\
\text { eksisting dan kolam } \\
\text { tampungan }\end{array}$} \\
\hline 1 & Saluran Drainase Eksisting & 1.2631 & 0.8867 & 1.0622 & & & & \\
\hline \multirow[t]{2}{*}{2} & Kolam Tampungan SMAN 2 & 0 & 0.4406 & 0.5278 & & & & \\
\hline & \multicolumn{3}{|c|}{ Reduksi Banjir Terpadu } & $(\%)$ & 100.00 & 100.00 & 100.00 & \\
\hline B. & DTA Rumah Pompa Sidokare & 2.2815 & 2.9647 & 3.5516 & & & & \multirow{4}{*}{$\begin{array}{l}\text { Kombinasi saluran } \\
\text { eksisting, kolam } \\
\text { tampungan dan } \\
\text { pompa banjir } \\
\text { eksisting }\end{array}$} \\
\hline 1 & Saluran Drainase Eksisting & 1.9678 & 2.0856 & 2.1737 & 86.25 & 70.35 & 61.20 & \\
\hline 2 & Kolam Tampungan Liponsos & 0.0576 & 0.4837 & 0.8677 & 2.53 & 16.32 & 24.43 & \\
\hline \multirow[t]{2}{*}{3} & Pompa Banjir Eksisting & 0.2561 & 0.3953 & 0.5102 & 11.22 & 13.34 & 14.37 & \\
\hline & \multicolumn{3}{|c|}{ Reduksi Banjir Terpadu } & $(\%)$ & 100.00 & 100.00 & 100.00 & \\
\hline C. & DTA Pintu Air Jl. Diponegoro & 2.8853 & 3.7395 & 4.4799 & & & & \multirow{5}{*}{$\begin{array}{l}\text { Kombinasi saluran } \\
\text { eksisting, saluran } \\
\text { tersier baru dan } \\
\text { pompa banjir baru }\end{array}$} \\
\hline 1 & Saluran Drainase Eksisting & 2.6105 & 2.9710 & 3.2117 & 90.48 & 79.45 & 71.69 & \\
\hline 2 & Saluran Tersier Baru 1 & 0.0944 & 0.2224 & 0.3318 & 3.27 & 5.95 & 7.41 & \\
\hline 3 & Saluran Tersier Baru 2 & 0.1782 & 0.4400 & 0.6682 & 6.17 & 11.77 & 14.92 & \\
\hline \multirow[t]{2}{*}{4} & Pompa Banjir Baru & 0.0023 & 0.1061 & 0.2683 & 0.08 & 2.84 & 5.99 & \\
\hline & \multicolumn{3}{|c|}{ Reduksi Banjir Terpadu } & $(\%)$ & 100.00 & 100.00 & 100.00 & \\
\hline
\end{tabular}

Tabel 4. Reduksi Banjir Setelah Dilakukan Penanganan Secara Terpadu

a. DTA Pintu Air Sepande

Debit banjir rencana kala ulang 1,01 tahun pada DTA Pintu Air Sepande sebesar $1,2631 \mathrm{~m}^{3} / \mathrm{dt}$, dapat ditangani seluruhnya dengan menggunakan saluran drainase eksisting yang ada (100\%). Sedangkan debit banjir rencana kala ulang 2 tahun $(1,3273$ $\mathrm{m}^{3} / \mathrm{dt}$ ), harus ditampung pada Kolam Tampungan SMAN 2 sebesar $0,4406 \mathrm{~m}^{3} / \mathrm{dt}$ $(33,20 \%)$ dan sisanya sebesar $0,8867 \mathrm{~m}^{3} / \mathrm{dt}$ $(66,80 \%)$ dialirkan melalui saluran drainase eksisting. Demikian pula untuk debit banjir rencana kala ulang 5 tahun $\left(1,5901 \mathrm{~m}^{3} / \mathrm{dt}\right)$, harus ditampung pada Kolam Tampungan SMAN 2 sebesar $0,5278 \mathrm{~m}^{3} / \mathrm{dt}(33,20 \%)$, dan sisanya sebesar $1,0622 \mathrm{~m} 3 / \mathrm{dt} \quad(66,80 \%)$ dialirkan melalui saluran drainase eksisting. Sehingga kombinasi keduanya akan dapat menangani genangan secara keseluruhan $(100 \%)$.

b. DTA Rumah Pompa Sidokare

Debit banjir rencana kala ulang 1,01 tahun pada DTA Rumah Pompa Sidokare sebesar 2,2815 $\mathrm{m}^{3} / \mathrm{dt}$, memerlukan kombinasi penanganan terpadu dengan menggunakan saluran drainase eksisting sebesar 1,9678 $\mathrm{m}^{3} / \mathrm{dt}(86,25 \%)$, Kolam Tampungan Liponsos sebesar $0,0576 \mathrm{~m}^{3} / \mathrm{dt}(2,53 \%)$ dan pompa banjir eksisting sebesar $0,2561 \mathrm{~m}^{3} / \mathrm{dt}$ $(11,22 \%)$. Sedangkan untuk penanganan debit banjir rencana kala ulang 2 tahun $\left(2,9647 \mathrm{~m}^{3} / \mathrm{dt}\right)$, menggunakan saluran drainase eksisting sebesar 2,0856 $\mathrm{m}^{3} / \mathrm{dt}$ (70,35\%), Kolam Tampungan Liponsos sebesar $0,4837 \mathrm{~m}^{3} / \mathrm{dt}(16,32 \%)$ dan pompa banjir eksisting sebesar $0,3953 \mathrm{~m}^{3} / \mathrm{dt}$ $(13,34 \%)$. Untuk debit banjir rencana kala ulang 5 tahun $\left(3,5516 \mathrm{~m}^{3} / \mathrm{dt}\right)$, menggunakan saluran drainase eksisting sebesar 2,1737 $\mathrm{m}^{3} / \mathrm{dt}(61,20 \%)$, Kolam Tampungan Liponsos sebesar $0,8677 \mathrm{~m}^{3} / \mathrm{dt}(24,43 \%)$ dan pompa banjir eksisting sebesar $0,5102 \mathrm{~m}^{3} / \mathrm{dt}$ $(14,37 \%)$. Sehingga kombinasi ketiganya akan dapat menangani genangan secara keseluruhan $(100 \%)$.

c. DTA Pintu Air Jl. Diponegoro

Debit banjir rencana kala ulang 1,01 tahun pada DTA Pintu Air Jl. Diponegoro sebesar $2,8853 \mathrm{~m}^{3} / \mathrm{dt}$, memerlukan kombinasi penanganan terpadu dengan menggunakan saluran drainase eksisting sebesar 2,6105 $\mathrm{m}^{3} / \mathrm{dt}(90,48 \%)$, Saluran Tersier Baru 1 sebesar $0,0944 \mathrm{~m}^{3} / \mathrm{dt} \quad(3,27 \%)$, Saluran Tersier Baru 2 sebesar 0,1782 $\mathrm{m}^{3} / \mathrm{dt}(6,17 \%)$ dan pompa banjir baru sebesar $0,0023 \mathrm{~m}^{3} / \mathrm{dt}$ $(0,08 \%$. 
Sedangkan untuk debit banjir rencana kala ulang 2 tahun $\left(3,7395 \mathrm{~m}^{3} / \mathrm{dt}\right)$, memerlukan kombinasi penanganan terpadu dengan menggunakan saluran drainase eksisting sebesar 2,9710 $\mathrm{m}^{3} / \mathrm{dt} \quad(79,45 \%)$, Saluran Tersier Baru 1 sebesar 0,2224 m³/dt (5,95\%), Saluran Tersier Baru 2 sebesar 0,4400 $\mathrm{m}^{3} / \mathrm{dt}$ $(11,77 \%)$ dan pompa banjir baru sebesar $0,1061 \mathrm{~m}^{3} / \mathrm{dt} \quad(2,84 \%)$. Pada debit banjir rencana kala ulang 5 tahun $\left(4,4799 \mathrm{~m}^{3} / \mathrm{dt}\right)$, memerlukan kombinasi penanganan terpadu dengan menggunakan saluran drainase eksisting sebesar $3,2117 \mathrm{~m}^{3} / \mathrm{dt} \quad(71,69 \%)$, Saluran Tersier Baru 1 sebesar 0,3318 $\mathrm{m}^{3} / \mathrm{dt}$ (7,41\%), Saluran Tersier Baru 2 sebesar $0,6682 \mathrm{~m}^{3} / \mathrm{dt}(14,92 \%)$ dan pompa banjir baru sebesar $0,2683 \mathrm{~m}^{3} / \mathrm{dt}(5,99 \%)$. Sehingga kombinasi keempatnya akan dapat menangani genangan secara keseluruhan $(100 \%)$.

\section{Perkiraan Biaya Penanganan Terpadu}

Berdasarkan hasil analisa, pengelolaan drainase secara terpadu di Kawasan Sidokare memerlukan biaya total sebesar Rp. 19.446.537.000,00. Di mana pengalokasian penanganannya dapat di-lakukan menurut urutan prioritas, daerah dengan dampak genangan historis terparah dan ketersediaan anggaran daerah. Besarnya perkiraan biaya penanganan terpadu dapat dilihat pada Tabel 5 .

Tabel 5. Perkiraan Biaya Penanganan Terpadu

\begin{tabular}{|c|c|c|c|}
\hline $\begin{array}{l}\text { Urutan } \\
\text { Prioritas }\end{array}$ & $\begin{array}{c}\text { Jenis } \\
\text { Penanganan }\end{array}$ & Lokasi & Biaya (Rp) \\
\hline 1 & $\begin{array}{l}\text { Pemeliharaan } \\
\text { rutin saluran } \\
\text { eksisting }\end{array}$ & $\begin{array}{l}\text { Kawasan } \\
\text { Sidokare }\end{array}$ & $\begin{array}{l}\text { Swakelola/ } \\
\text { Swadaya }\end{array}$ \\
\hline 2 & $\begin{array}{l}\text { Kolam } \\
\text { Tampungan } \\
\text { Liponsos }\end{array}$ & $\begin{array}{c}\text { DTA Rumah } \\
\text { Pompa Sidokare }\end{array}$ & $11.239 .795 .000,00$ \\
\hline 3 & $\begin{array}{l}\text { Pompa banjir } \\
\text { baru }\end{array}$ & $\begin{array}{l}\text { DTA Pintu Air } \\
\text { Jl. Diponegoro }\end{array}$ & $611.754 .000,00$ \\
\hline 4 & $\begin{array}{l}\text { Saluran } \\
\text { Tersier Baru } 1\end{array}$ & $\begin{array}{l}\text { DTA Pintu Air } \\
\text { Jl. Diponegoro }\end{array}$ & $406.327 .000,00$ \\
\hline 5 & $\begin{array}{l}\text { Saluran } \\
\text { Tersier Baru } 2\end{array}$ & $\begin{array}{l}\text { DTA Pintu Air } \\
\text { Jl. Diponegoro }\end{array}$ & $1.158 .763 .000,00$ \\
\hline 6 & $\begin{array}{l}\text { Kolam } \\
\text { Tampungan } \\
\text { SMAN } 2\end{array}$ & $\begin{array}{c}\text { DTA Pintu Air } \\
\text { Sepande }\end{array}$ & $6.029 .896 .000,00$ \\
\hline \multicolumn{3}{|c|}{ Jumlah } & 19.446.537.000,00 \\
\hline
\end{tabular}

\section{KESIMPULAN}

Dari analisis yang telah dilakukan, diperoleh kesimpulan sebagai berikut:

1. Banjir historis di Kawasan Sidokare disebabkan oleh curah hujan dengan nilai intensitas sebesar $17,55 \mathrm{~mm} / \mathrm{jam}$. Nilai tersebut mendekati hasil perhitungan intensitas hujan rencana kala ulang 1,01 tahun, yaitu sebesar $16,503 \mathrm{~mm} / \mathrm{jam}$.

2. Dengan adanya parapet (tanggul sungai tambahan) setinggi $0,5 \mathrm{~m}$ dan penanganan terpadu menggunakan saluran drainase eksisting, kolam tampungan dan saluran tersier baru, maka sisa volume banjir yang harus dipompa dari Kawasan Sidokare ke Afvoer Sidokare masih dalam kategori aman, karena pada kala ulang 1,01 tahun, 2 tahun dan 5 tahun, tinggi muka air di afvoer bertambah $0,05 \mathrm{~m}, 0,10 \mathrm{~m}$ dan $0,15 \mathrm{~m}$ dari muka air maksimum (puncak tanggul lama).

3. Bentuk pengelolaan drainase secara terpadu untuk Kawasan Sidokare, disesuaikan dengan kondisi masingmasing DTA. Untuk DTA Pintu Air Sepande menggunakan salu ran drainase eksisting dan kolam tampungan. DTA Rumah Pompa Sidokare, kombinasi saluran drainase eksisting, kolam tampungan dan pompa banjir eksisting. Dan DTA Pintu Air Jl. Diponegoro, kombinasi saluran drainase eksisting, saluran tersier baru, dan pompa banjir baru.

4. Reduksi banjir di Kawasan Sidokare setelah dilakukan penanganan secara terpadu memiliki tingkat keberhasilan hingga $100 \%$. Sehingga dengan adanya penanganan secara terpadu tersebut, permasalahan genangan di lokasi studi diharapkan dapat segera diatasi.

5. Perkiraan biaya konstruksi untuk penanganan terpadu di Kawasan Sidokare adalah sebesar Rp. 19.446.537.000,00. Dengan rincian, DTA Pintu Air Sepande sebesar Rp. 6.029.896.000,00, DTA Rumah Pompa Sidokare sebesar Rp. 11.239.795.000,00 dan DTA Pintu Air Jl. Diponegoro sebesar Rp. 2.176.846.000,00. 


\section{UCAPAN TERIMA KASIH}

Dr. Ery Suhartanto, ST.MT. selaku Ketua Program Studi Magister Teknik Pengairan Universitas Brawijaya. Kementerian Pekerjaan Umum dan Perumahan Rakyat, atas beasiswa kedinasan program magister. Badan Kepegawaian Daerah Kabupaten Sidoarjo, Dinas Pekerjaan Umum Pengairan Kabupaten Sidoarjo dan instansi terkait lainnya. Serta teman-teman Karyasiswa Kementerian Pekerjaan Umum dan Perumahan Rakyat Program Magister Sumber Daya Air.

\section{DAFTAR PUSTAKA}

Ariyanto, Didid, Donny Harisuseno dan Rini Wahyu Sayekti. 2012. Studi Pengendalian Banjir Kota Tanjung Selor Kabupaten Bulungan Provinsi Kalimantan Timur. Tesis. Tidak Dipublikasikan. Universitas Brawijaya, Malang.

Ditjen Cipta Karya Kementerian Pekerjaan Umum. 2012. Buku Sistem Drainase
Perkotaan. Kementerian Pekerjaan Umum, Jakarta.

Putri, Rianti Dwi, Dwi Priyantoro, Linda Prasetyorini dan Heri Suprijanto. 2014. Evaluasi Sistem Drainase Daerah Muara Boezem Utara Morokrembangan Surabaya. Skripsi. Tidak Dipublikasikan. Universitas Brawijaya, Malang.

Rahmawati, Anita, Alia Damayanti dan Eddy Setiadi Soedjono. 2015. Evaluasi Sistem Drainasi Terhadap Penanggulangan Genangan di Kota Sidoarjo. Prosiding Seminar Nasional Aplikasi Teknologi Prasarana Wilayah (ATPW). Surabaya, 11 Juni 2015.

Suripin. 2004. Sistem Drainase Perkotaan Yang Berkelanjutan. Andi Offset, Yogyakarta.

Suhardjono. 2015. Drainase Perkotaan. Universitas Brawijaya, Malang. 